\title{
Damaged self-esteem is associated with internalizing problems
}

\section{Daan H. M. Creemers ${ }^{1,2}{ }^{*}$, Ron H. J. Scholte ${ }^{2}$, Rutger C. M. E. Engels ${ }^{2}$, Mitchell J. Prinstein $^{3}$ and Reinout W. Wiers ${ }^{4}$}

1 Mental Health Care Institute, GGZ Oost-Brabant, Veghel, Netherlands

${ }^{2}$ Behavioural Science Institute, Radboud University Nijmegen, Nijmegen, Netherlands

${ }^{3}$ University of North Carolina at Chapel Hill, Chapel Hill, NC, USA

${ }^{4}$ Addiction, Development, and Psychopathology-Lab, Department of Psychology, University of Amsterdam, Amsterdam, Netherlands

\section{Edited by:}

Natalie L. Denburg, The University of lowa, USA

Reviewed by:

Brian Ostafin, University of Groningen, Netherlands

Lisa D. Hawke, Université Laval,

Canada

*Correspondence:

Daan H. M. Creemers, Behavioural Science Institute, Radboud University Nijmegen, 6500 HE Nijmegen,

Netherlands.

e-mail:d.creemers@pwo.ru.nl
Implicit and explicit self-esteem are assumed to be important factors in understanding the onset and maintenance of psychological problems. The current study aims to examine the association between implicit and explicit self-esteem and their interaction with depressive symptoms, suicidal ideation, and loneliness. Specifically, the relationship between the size and the direction of the discrepancy between implicit and explicit self-esteem with depressive symptoms, suicidal ideation, and loneliness were examined. Participants were 95 young female adults $(M=21.2$ years, $S D=1.88)$ enrolled in higher education. We administered the IAT to assess implicit self-esteem, and the Rosenberg self-esteem scale to measure explicit self-esteem while psychological problems were assessed through selfreports. Results showed that discrepancies between implicit and explicit self-esteem were positively associated with depressive symptoms, suicidal ideation, and loneliness. In addition, the direction of the discrepancy was specifically relevant: damaged self-esteem (i.e., high implicit self-esteem and low explicit self-esteem) was consistently associated with increased levels of depressive symptoms, suicidal ideation, and loneliness. In contrast, defensive or fragile self-esteem (i.e., low implicit and high explicit self-esteem) was solely associated with loneliness. These findings provide further support that specifically damaged self-esteem is an important vulnerability marker for depressive symptoms, suicidal ideation, and loneliness.

Keywords: damaged, implicit cognition, self-esteem, suicidal ideation, depression, loneliness

\section{INTRODUCTION}

Self-esteem plays a crucial role in the onset and maintenance of internalizing problems (Harter, 1993; Brage and Meredith, 1994; Prinstein and La Greca, 2002; Evans et al., 2004). Research has mainly focused on the association of explicit self-esteem with internalizing problems, whereas there is growing evidence that implicit self-esteem might be an important construct to examine in relation to internalizing problems. Implicit self-esteem is defined as relatively automatic, overlearned, and non-conscious evaluation of the self that guides spontaneous reactions to self-relevant stimuli (Greenwald and Banaji, 1995). Implicit self-esteem is a complex, multi-dimensional construct (Koole and Pelham, 2003) and, therefore, it has been argued that various measures of implicit selfesteem may be addressing different facets of this construct. Moreover, in the field of research on implicit and explicit self-esteem results often show that, in addition to its unique associations, the discrepancy between implicit and explicit self-esteem is considered to be relevant for understanding psychopathology. A recent study (Creemers et al., 2012) showed that discrepancies between implicit and explicit self-esteem were positively associated with depressive symptoms, suicidal ideation, and loneliness. In addition, the direction of the discrepancy has been found to be specifically relevant: damaged self-esteem (high implicit self-esteem and low explicit self-esteem) was related to increased levels of depressive symptoms, suicidal ideation, and loneliness, while defensive or fragile self-esteem (low implicit self-esteem and high explicit self-esteem) was not.

In order to understand how asymmetric changes between implicit and explicit self-esteem develop, dual process models provide an useful theoretical framework. According to recent dual process models, two distinct information-processing modes with different operating principles can be distinguished: the reflective and the associative mode (Epstein, 1994; Gawronski and Bodenhausen, 2006). Explicit self-esteem reflects a product of the reflective mode, shaped through rational and conscious processing of self-relevant stimuli, whereas implicit self-esteem is assumed to be the outcome of the associative mode, shaped through more automatic, intuitive, unconscious processing of affective experiences (Epstein and Morling, 1995; Dijksterhuis, 2006). As a result of the distinct cognitive processes asymmetric changes (for example, decrease in explicit self-esteem but not in implicit self-esteem) between implicit and explicit self-esteem may occur. It has been proposed that damaged self-esteem in depressed individuals may represent a discrepancy between "the ideal self" and "the actual self." Implicit self-esteem, which is proposed to develop earlier in interaction with primary care givers (e.g., DeHart et al., 2006), may 
be indicative for the "ideal self." Subsequently, explicit self-esteem may be indicative for the more recently formed "actual self." As a result of the discrepancy people may feel entrapped between their goals and "reality" which in turn may lead to internalizing problems.

Two common measures to assess implicit self-esteem are the Name Letter Task (NLT) and the Implicit Association Test (IAT). Implicit self-esteem as conceptualized by the NLT is supposed to assess an aspect of implicit self-esteem that differs from the IAT and, therefore, these two measures are not correlated with each other (Bosson et al., 2000). Importantly, implicit self-esteem is defined as the relatively automatic, overlearned, and nonconscious evaluation of the self that guides spontaneous reactions to self-relevant stimuli (Greenwald and Banaji, 1995). The finding that both measures of implicit self-esteem are not related might be due to the distinct self-relevant stimuli that are being used in the IAT and NLT. To illustrate, the IAT measures the strength of the association between "the self" and "worthless" or "valuable," while the NLT asses the relative preference for one's own initials assuming these stem from self-associations in memory. Although previous studies showed that both measures of implicit self-esteem were not correlated (Bosson et al., 2000), similar associations between the two measures and internalizing problems were found (e.g., Franck et al., 2007; Creemers et al., 2012). This might indicate that both aspects of implicit self-esteem are part of an analogous underlying mechanism that is associated with the onset and development of internalizing problems. Therefore, in order to gain a full perspective of the associations between implicit selfesteem and internalizing problems the use of multiple implicit measures is relevant.

In the Creemers et al. (2012) paper implicit self-esteem was measured with the NLT. In the present study we will report on the associations of implicit self-esteem and explicit self-esteem (and their discrepancy) with psychopathology using different implicit measures. The measures we used to assess implicit self-esteem were two versions of the IAT (Greenwald et al., 1998; Sriram and Greenwald, 2009). Our aim was to test whether the findings reported in Creemers et al. (2012) could be extended by using these different measures of implicit self-esteem. We hypothesized that specifically damaged self-esteem was associated with internalizing problems.

\section{MATERIALS AND METHODS PARTICIPANTS}

All participants volunteered to participate in the study after informed consent. Participants were 95 female undergraduate students of a College for Higher Professional Education, in The Netherlands ${ }^{1}$. Their mean age was 21.2 years $(\mathrm{SD}=1.88$, Range $=19-30$ ).

\section{PROCEDURE}

Prior to the data collection all participants were told that the experiment examined various predictors of human emotion. First, a computerized implicit measure, the IAT was administered. After completing this task, the computerized explicit self-esteem scale

\footnotetext{
${ }^{1}$ The same sample as in the Creemers et al. (2012) study was used.
}

was assessed. Next, participants completed questionnaires on depressive symptoms, suicidal ideation, and loneliness.

\section{MEASURES \\ Explicit self-esteem}

The Rosenberg self-esteem scale (RSES; Rosenberg, 1965) was used to assess global feelings of self-esteem (e.g., "I feel I do not have much to be proud of"). This self-report questionnaire consists of 10 items measured on a 4-point scale (totally agree - totally disagree). Validity and test-retest reliability of the RSES are satisfactory (Franck et al., 2008). Cronbach's $\alpha$ was 0.87 for the present sample.

\section{Implicit self-esteem}

Implicit association test. The IAT measures associations between four categories by pairing two target categories (i.e., me/not-me) with two attribution categories (i.e., valuable/worthless; Greenwald et al., 1998). The underlying assumption of the IAT is that when certain concepts (i.e., valuable and me) are more strongly associated in memory than other concepts (i.e., valuable and not$\mathrm{me})$, responses are faster when these concepts share a response key. Thus, the faster the response time, the stronger the presumed association is between two categories in memory. In our study, "valuable" and "me" sharing one response key, and "worthless" and "not-me," sharing another response key, was the compatible block. The incompatible block consisted of "valuable" and "not-me" sharing one response key, and "worthless" and "me" sharing another response key. The mean difference in reaction times between compatible and incompatible trials is used to estimate the IAT effect: the relative associative strength between the two pairs of concepts. The IAT consisted of seven blocks of trials, and similar stimuli were used as described by Franck et al. (2007). The improved scoring algorithm (Greenwald et al., 2003) was used (D600 algorithm) to compute the individual effect size of the subjects. In our study, higher scores indicated higher levels of implicit self-esteem. Past research demonstrated satisfactory reliability and validity of the IAT (Greenwald et al., 1998; Nosek et al., 2005). The IAT was programed in Inquisit 3.0 (Millisecond software). As an index of internal consistency for the IAT we computed the correlation between the test and practice blocks. A significant correlation was found $(r=0.62 ; p<0.001)$.

\section{Depressive symptoms}

A Dutch version of the Beck Depression Inventory (BDI-II; Beck et al., 1996; Van der Does, 2002) was administered to measure the severity of depressive symptoms. Satisfactory validity and psychometric properties of this scale were demonstrated in previous research (Van der Does, 2002). This self-report questionnaire consists of 21 items assessed on a 4-point scale, with items ranging from 0 to 3. Cronbach's $\alpha$ was 0.89 .

\section{Suicidal ideation}

Participants completed a Dutch version of the questionnaire developed by Heilbron and Prinstein (2010) to measure suicidal ideation. This self-report measure assesses suicidal thoughts in adolescents and young adults (e.g., "I thought that killing myself would solve my problems"). This scale consists of 16 
items measured on a 5-point scale (never - almost every day), and includes a subset of items drawn from the Suicidal Ideation Questionnaire (SIG; Reynolds, 1988) and the NIMH-DISC-IV (Shaffer et al., 2000). Cronbach's $\alpha$ was 0.89 .

\section{Loneliness}

A short version (R-ULS-8, Roberts et al., 1993) of the revised UCLA Loneliness Scale (R-ULS; Russell et al., 1980) was used to assess loneliness. Satisfactory construct validity and reliability were found in other adolescent populations (Higbee and Roberts, 1994). This instrument consists of 8-items (e.g., "I feel left out") assessed on a 5-point scale (I totally disagree - totally agree). Cronbach's $\alpha$ was 0.84 .

\section{DATA ANALYSES}

First, a series of hierarchical multiple regression analyses were performed to examine the relationship between implicit, explicit self-esteem, and their interaction with suicidal ideation, depressive symptoms, and loneliness. Implicit and explicit self-esteem were entered in step 1 and their interaction in step 2. Second, we examined the relationship of implicit-explicit discrepancies with depressive symptoms, suicidal ideation, and loneliness. The absolute difference between the standardized score on implicit and explicit self-esteem was computed, which indicated the size of the discrepancy. A higher score on this variable was indicative for a larger implicit-explicit self-esteem discrepancy. Next, a dummy variable was computed to determine the direction of the discrepancy between implicit and explicit self-esteem (implicit $<$ explicit or implicit > explicit; dummy code). In the present study, 49 participants showed higher implicit than explicit self-esteem, and 46 participants reported higher explicit than implicit self-esteem. In order to examine whether implicit-explicit self-esteem discrepancies were related to suicidal ideation, depressive symptoms, and loneliness, a series of hierarchical multiple regression analyses were performed. The size of the discrepancy and the direction of the discrepancy (dummy) were entered in step 1 and their interaction in step 2. As argued in several recent papers (Briñol et al., 2006; Schröder-Abé et al., 2007; Creemers et al., 2012), these discrepancy analyses are an appropriate manner of specifically testing the associations of implicit-explicit self-esteem discrepancies with internalizing problems. ${ }^{2}$ Interactions were tested using the procedure proposed by Aiken and West (1991).

\section{RESULTS}

\section{INTERCORRELATIONS AMONG THE MEASURES}

Descriptive statistics of all study variables were presented in Table 1. The intercorrelations among all study measures are displayed in Table 2. The measures of implicit and explicit self-esteem were weakly correlated. Next, explicit self-esteem was negatively correlated to depressive symptoms, suicidal ideation, and loneliness. Depressive symptoms, suicidal ideation, and loneliness were positively correlated.

\footnotetext{
${ }^{2}$ As described in Creemers et al. (2012), variables of the conventional regression model and the discrepancy regression model need to be examined separately. These are separate models and, therefore, including the main effects of implicit and explicit self-esteem within the discrepancy regression model, would have led to a multicollinearity problem and to uninterpretable results.
}

Table 1 | Descriptive statistics for measures of implicit and explicit self-esteem, depressive symptoms, suicidal ideation, and loneliness.

\begin{tabular}{lrcccr}
\hline & Mean & SD & Range & Min & Max \\
\hline Impl. self-esteem (IAT) & 0.79 & 0.47 & $* * *$ & -0.81 & 1.86 \\
Expl. self-esteem & 30.65 & 4.42 & $10-40$ & 18.00 & 40.00 \\
Depressive symptoms & 8.29 & 7.32 & $00-63$ & 0.00 & 34.00 \\
Suicidal ideation & 8.47 & 1.72 & $16-80$ & 8.00 & 21.00 \\
Loneliness & 14.49 & 5.46 & $8-40$ & 8.00 & 30.00 \\
\hline
\end{tabular}

Table 2 | Correlations among measures of implicit and explicit self-esteem, depressive symptoms, suicidal ideation, and loneliness.

\begin{tabular}{lcclll}
\hline & $\mathbf{1}$ & $\mathbf{2}$ & $\mathbf{3}$ & $\mathbf{4}$ & $\mathbf{5}$ \\
\hline Impl. self-esteem (IAT) & - & & & \\
Expl. self-esteem & $0.23^{*}$ & - & & \\
Depressive symptoms & $-0.23^{*}$ & $-0.70^{* *}$ & - & \\
Suicidal ideation & 0.05 & $-0.36^{* *}$ & $0.38^{* *}$ & - \\
Loneliness & $-0.24^{*}$ & $-0.67^{* *}$ & $0.60^{* *}$ & $0.29^{* *}$ & -
\end{tabular}

${ }^{*} p<0.05 ;{ }^{* *} p<0.01$.

In addition to the conventional IAT, the Brief IAT (Sriram and Greenwald, 2009) was administered to assess implicit self-esteem. A significant correlation was found between the IAT and Brief IAT $\left(r=0.48^{* *}\right)$. Results of the analyses with the Brief IAT are similar as the presented results with the IAT, and therefore only available in an online Appendix.

\section{ASSOCIATIONS WITH EXPLICIT AND IMPLICIT SELF-ESTEEM}

As presented in Table 3, results of step 1 show that explicit self-esteem significantly predicts unique variance in depressive symptoms $(\beta=-0.69, p<0.001)$, suicidal ideation $(\beta=-0.44$, $p<0.001)$, and loneliness $(\beta=-0.65, p<0.001)$. No significant associations of implicit self-esteem were found with depressive symptoms $(\beta=-0.06, p=0.40)$ suicidal ideation $(\beta=0.17$, $p=0.08)$, and loneliness $(\beta=-0.08, p=0.31)$.

\section{ASSOCIATIONS OF THE INTERACTION BETWEEN IMPLICIT AND EXPLICIT SELF-ESTEEM}

In step 2 we entered the interaction between implicit and explicit self-esteem. Results showed no significant associations of the interaction between implicit and explicit self-esteem with depressive symptoms $(\beta=0.07, p=0.35)$, suicidal ideation $(\beta=-0.10$, $p=0.30)$, and loneliness $(\beta=0.06, p=0.50)$. Table 3 summarizes the results of the multiple hierarchical regression analyses.

\section{ASSOCIATIONS OF IMPLICIT-EXPLICIT DISCREPANCIES}

First, in participants with damaged self-esteem we found significant correlations between the size of the discrepancy and depressive symptoms $\left(r=0.68^{* *}\right)$, suicidal ideation $\left(r=0.31^{*}\right)$, and loneliness $\left(r=0.35^{*}\right)$, while in participants with fragile selfesteem no significant correlations were found. Second, a series of multiple hierarchical regression analyses were performed with the size of the discrepancy and the direction of the discrepancy (dummy coded) entered in step 1, and their interaction entered in 
Table 3 | Hierarchical multiple regression analyses: associations of explicit self-esteem, implicit self-esteem, and the Interaction between implicit and explicit self-esteem with suicidal ideation, depressive symptoms, and loneliness.

\begin{tabular}{|c|c|c|c|c|c|c|c|c|c|}
\hline & \multicolumn{3}{|c|}{ Suicidal ideation } & \multicolumn{3}{|c|}{ Depressive symptoms } & \multicolumn{3}{|c|}{ Loneliness } \\
\hline & B & SE & $\beta$ & B & SE & $\beta$ & B & SE & $\beta$ \\
\hline \multicolumn{10}{|l|}{ STEP 1} \\
\hline Implicit self-esteem & 0.01 & 0.01 & 0.17 & -0.06 & 0.08 & -0.06 & -0.08 & 0.08 & -0.08 \\
\hline Explicit self-esteem & -0.03 & 0.01 & $-0.44^{* *}$ & -0.69 & 0.08 & $-0.69 * *$ & -0.65 & 0.08 & $-0.65^{* *}$ \\
\hline \multicolumn{10}{|l|}{ STEP 2} \\
\hline Implicit self-esteem* & -0.01 & 0.01 & -0.10 & 0.05 & 0.06 & 0.07 & 0.04 & 0.06 & 0.06 \\
\hline Explicit self-esteem & & & & & & & & & \\
\hline
\end{tabular}

Suicidal ideation $R^{2}=0.18$ in step $1(p=0.00) ; \Delta R^{2}=0.01$ in step $2(p=0.31)$; depressive symptoms $R^{2}=0.49$ in step $1(p=0.00) ; \Delta R^{2}=0.01$ in step $2(p=0.35)$; loneliness $R^{2}=0.46$ in step $1(p=0.00) ; \Delta R^{2}=0.00$ in step $2(p=0.49) ;{ }^{*} p<0.05{ }^{*} p<0.01$.

Table 4 | Hierarchical multiple regression analyses: associations of the size of the discrepancy, direction of the discrepancy, and the interaction between the size of the discrepancy and the direction of the discrepancy with suicidal ideation, depressive symptoms, and loneliness.

\begin{tabular}{|c|c|c|c|c|c|c|c|c|c|}
\hline & \multicolumn{3}{|c|}{ Suicidal ideation } & \multicolumn{3}{|c|}{ Depressive symptoms } & \multicolumn{3}{|c|}{ Loneliness } \\
\hline & B & SE & $\beta$ & B & SE & $\beta$ & B & SE & $\beta$ \\
\hline Size of the discrepancy & 0.02 & 0.01 & $0.25^{*}$ & 0.35 & 0.13 & $0.28 * *$ & 0.06 & 0.13 & 0.05 \\
\hline Direction of the discrepancy & 0.04 & 0.01 & $0.28^{* *}$ & 0.28 & 0.20 & 0.14 & 0.39 & 0.21 & 0.20 \\
\hline \multicolumn{10}{|l|}{ STEP 2} \\
\hline
\end{tabular}

Suicidal ideation $R^{2}=0.14$ in step $1(p=0.00) ; \Delta R^{2}=0.06$ in step $2(p=0.01)$; depressive symptoms $R^{2}=0.09$ in step $1(p=0.01) ; \Delta R^{2}=0.17$ in step $2(p=0.00)$; loneliness $R^{2}=0.04$ in step $1(p=0.15) ; \Delta R^{2}=0.10$ in step $2(p=0.00) ;{ }^{*} p<0.05{ }^{* *} p<0.01$. Direction of the discrepancy was dummy coded: $0=$ fragile self-esteem; $1=$ damaged self-esteem.

step 2 (see text footnote 2). As shown in Table 4, the size of the discrepancy was positively associated with depressive symptoms $(\beta=0.28, p<0.01)$, and suicidal ideation $(\beta=0.25, p=0.01)$. There was no significant relationship of the size of the discrepancy with loneliness $(\beta=0.05, p=0.66)$. The direction of the discrepancy was significantly associated with suicidal ideation $(\beta=0.28$, $p<0.01)$, whereas no associations with depressive symptoms ( $\beta=0.14, p=0.16)$ or loneliness $(\beta=0.20, p<0.06)$ were found. Moreover, the interaction between the size of the discrepancy and the direction of the discrepancy was related to depressive symptoms $(\beta=0.77, p<0.001)$, suicidal ideation $(\beta=0.45, p<0.05)$, and loneliness $(\beta=0.60, p<0.01)$. Similarly, as in Creemers et al. (2012), significant associations were found between the size of the discrepancy and all measured internalizing problems in participants with damaged self-esteem (higher implicit then explicit selfesteem). Participants with fragile self-esteem (higher explicit then implicit self-esteem) showed no significant associations between the size of the discrepancy and depressive symptoms or suicidal ideation. However, we did find that the size of the discrepancy was negatively associated with loneliness in participants with fragile self-esteem. In sum, these findings indicate that damaged selfesteem is related to higher levels of depressive symptoms, suicidal ideation, and loneliness, whereas fragile self-esteem is solely related to lower levels of loneliness (Figures 1-3).

\section{DISCUSSION}

The main purpose of the present study was to test whether recent findings regarding implicit self-esteem and the discrepancy between implicit and explicit self-esteem as concurrent predictors of internalizing problems (Creemers et al., 2012) could be extended by using a different measure of implicit self-esteem. Additional measures to assess implicit self-esteem (i.e., IAT and Brief IAT) were administered and used to validate our findings. Results showed that explicit self-esteem was negatively associated with depressive symptoms, suicidal ideation, and loneliness, whereas no unique associations of this assessment of implicit self-esteem with internalizing problems were found. Next, the relationship of the size and the direction of the discrepancy between implicit and explicit self-esteem, and their interaction with depressive symptoms, suicidal ideation, and loneliness were examined. As expected, results showed that the size of the discrepancy was positively associated with all indices of internalizing problems, specifically, in participants with damaged self-esteem (higher implicit than explicit self-esteem). In addition, for participants with defensive or fragile self-esteem (high explicit and low implicit self-esteem) we found that the size of the discrepancy was negatively associated with loneliness. Importantly, these findings indicate that damaged self-esteem is an important vulnerability marker for the onset and development of internalizing problems. 


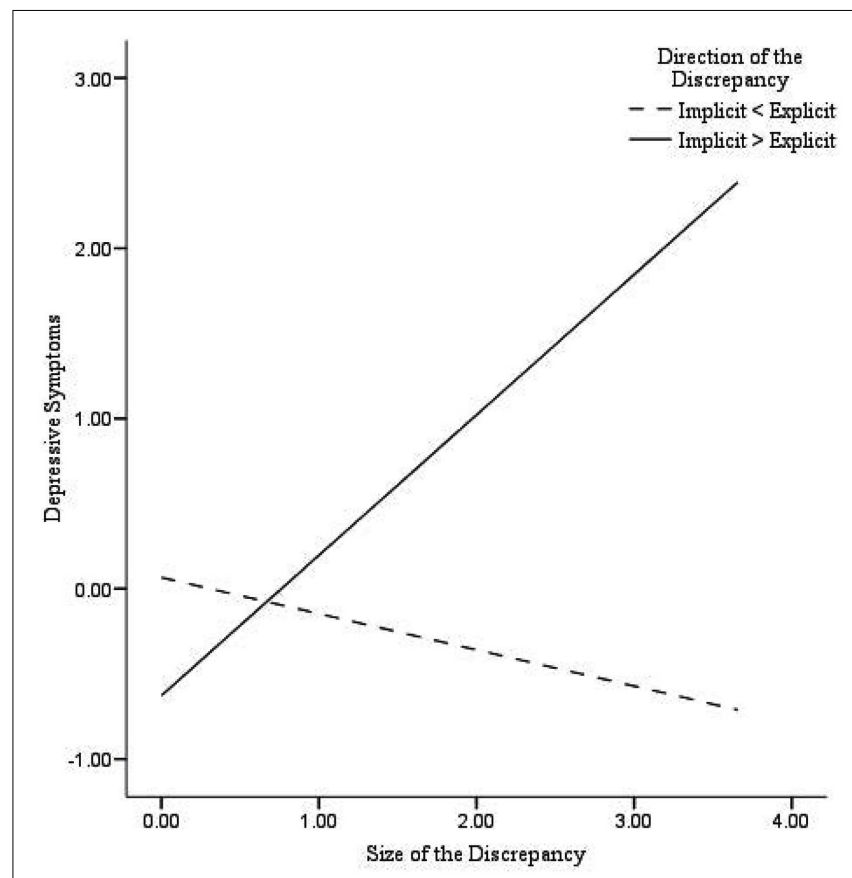

FIGURE 1 | Predicted values for depressive symptoms, illustrating the interaction between the size of the discrepancy and the direction of the discrepancy.

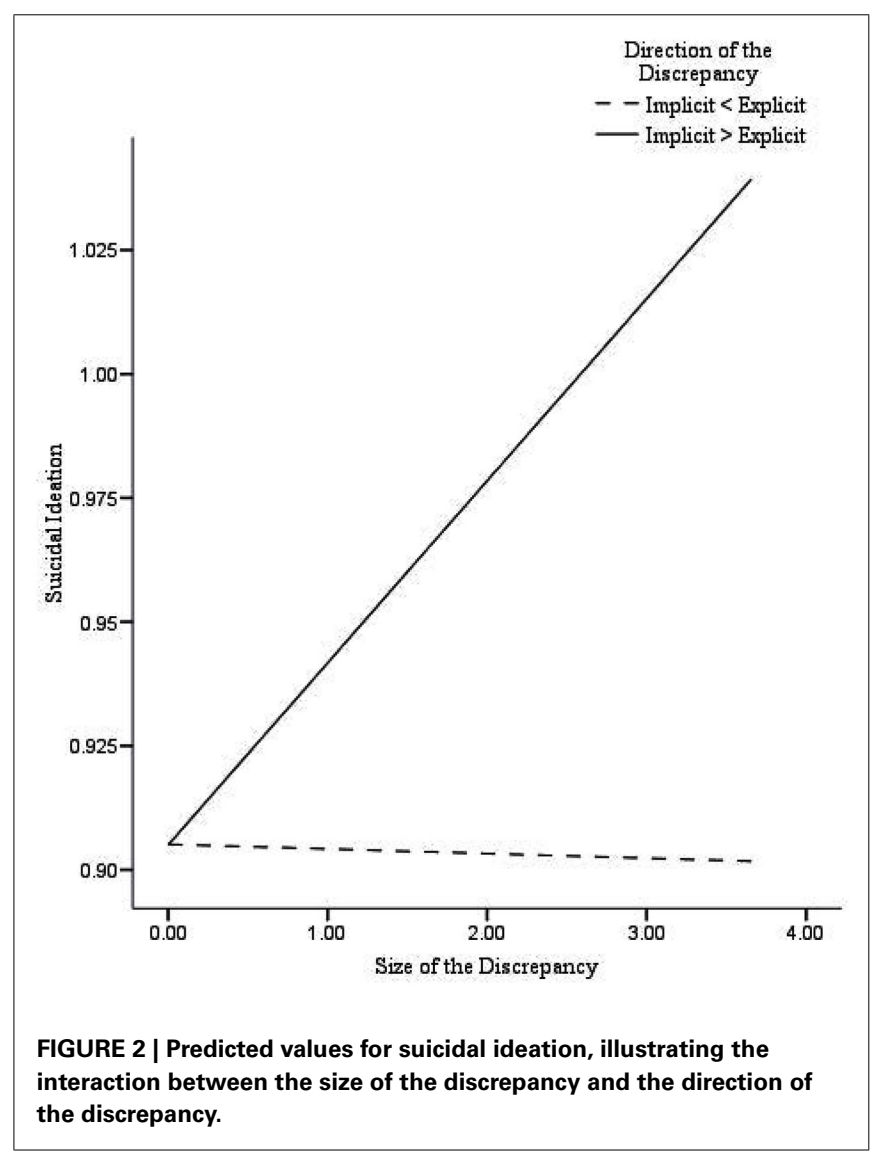

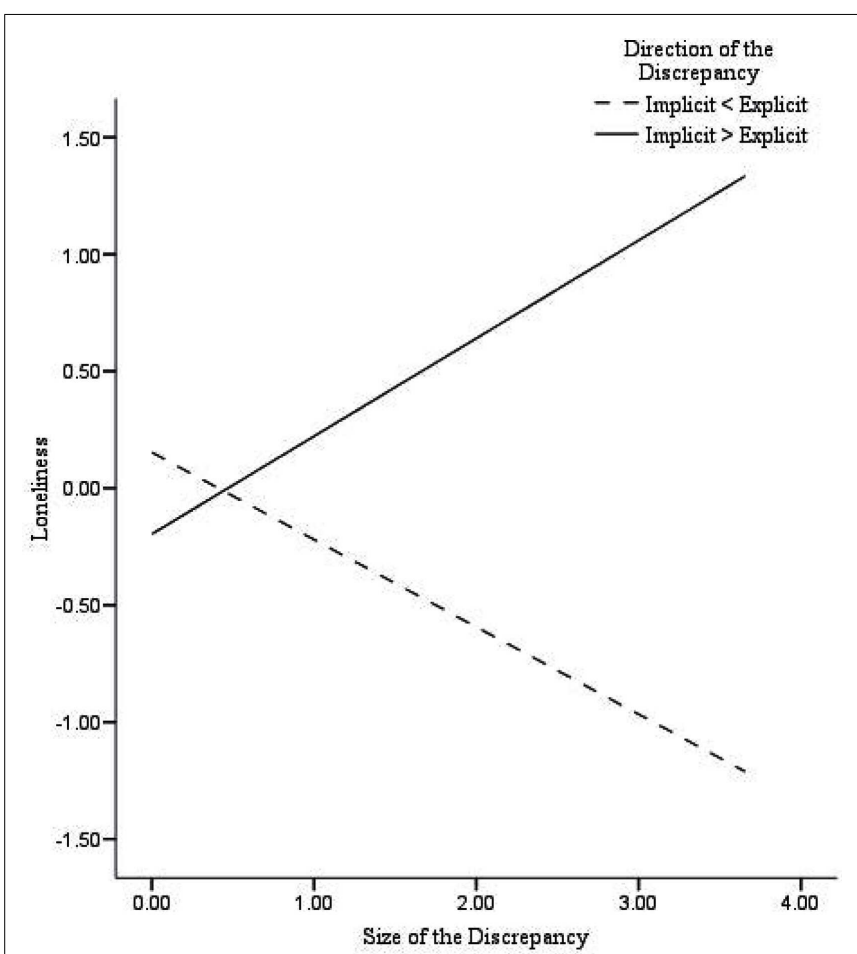

FIGURE 3 | Predicted values for loneliness, illustrating the interaction between the size of the discrepancy and the direction of the discrepancy.

Overall, these findings confirm previous results that were presented in Creemers et al. (2012), however, they also extend current literature in several aspects. More specifically, our finding that damaged self-esteem is associated with depressive symptoms, suicidal ideation, and loneliness when implicit self-esteem is measured with the IAT is relevant. This further supports the assumption that discrepancies between implicit and explicit selfesteem are important to consider for understanding internalizing psychopathology. Subsequently, we think that current findings emphasize the use of implicit measures to examine (implicit) cognitive processes in relation to the maintenance and treatment of internalizing problems. For example, the therapeutic effect of Cognitive Behavior Therapy (CBT) might be different for individuals with discrepancies between implicit and explicit self-esteem. The enhancement of explicit self-esteem might be useful for individuals with damaged self-esteem (high implicit and low explicit), whereas it might be disadvantageous for individuals with fragile self-esteem (low implicit and high explicit self-esteem). More specifically, it might be possible that individuals with fragile selfesteem have more benefit from interventions that increase implicit self-esteem, because congruent high self-esteem (high implicit and explicit self-esteem) has been found to be an important predictor for psychological wellbeing (e.g., Jordan et al., 2003; Kernis et al., 2008). Furthermore, research into mechanisms that enhance the congruence between implicit and explicit self-esteem seems relevant. Recently, Koole et al. (2009) found that meditation appears to be effective to reduce implicit-explicit discrepancies 
(i.e., self-esteem). In addition, mindfulness training is aimed to enhance the clarity of thoughts, feelings, behaviors, and sensations of individuals (Brown et al., 2007). Since, Chiesa and Serretti (2009) showed that mindfulness training leads to decreased levels of stress, it might be of interest to examine the effect of mindfulness training on implicit-explicit discrepancies.

One limitation of the present study is that as a result of the cross-sectional design no conclusions with regard to causality

\section{REFERENCES}

Aiken, L., and West, S. (1991). Multiple Regression: Testing and Interpreting Interaction. Newbury Park, CA: Sage.

Beck, A. T., Steer, R. A., and Brown, G. K. (1996). Manual for the Beck Depression Inventory-Second edition. San Antonio, TX: The Psychological Corporation.

Bosson, J. K., Swann, W. B., and Pennebaker, J. W. (2000). Stalking the perfect measure of implicit selfesteem: the blind men and the elephant revisited? J. Pers. Soc. Psychol. 79, 631-643.

Brage, D., and Meredith, W. (1994). A causal model of adolescent depression. J. Psychol. 128, 455-468.

Briñol, P., Petty, R. E., and Wheeler, S. C. (2006). Discrepancies between explicit and implicit self-concepts: consequences for information processing. J. Pers. Soc. Psychol. 91, 154-170.

Brown, K. W., Ryan, R. M., and Creswell, J. D. (2007). Mindfulness: theoretical foundations and evidence for its salutary effects. Psychol. Inq. 18, 21-37.

Chiesa, A., and Serretti, A. (2009). Mindfulness-based stress reduction for stress management in healthy people: a review and meta-analysis. J. Altern. Complement. Med. 15, 593-600.

Creemers, D. H. M., Scholte, R. H. J., Engels, R. C. M. E., Prinstein, M. J., and Wiers, R. W. (2012). Implicit and explicit self-esteem as concurrent predictors of suicidal ideation, depressive symptoms and loneliness. J. Behav. Ther. Exp. Psychiatry 43, 638-646.

DeHart, T., Pelham, B. W., and Tennen, H. (2006). What lies beneath: parenting style and implicit self-esteem. J. Exp. Soc. Psychol. 42, 1-17.

Dijksterhuis, A. (2006). The emergence of implicit self-esteem. Neth. J. Psychol. 62, 19-25.

Epstein, S. (1994). Integration of the cognitive and the psychodynamic unconscious. Am. Psychol. 49, 709-724.

Epstein, S., and Morling, B. (1995). "Is the self motivated to do more than enhance and/or verify itself?" in
Efficacy, Agency, and Self-Esteem, ed. M. H. Kernis (New York: Plenum), 9-29.

Evans, E., Hawton, K., and Rodham, K. (2004). Factors associated with suicidal phenomena in adolescents: a systematic review of populationbased studies. Clin. Psychol. Rev. 24, 957-979.

Franck, E., De Raedt, R., Barbez, C., and Rosseel, Y. (2008). Psychometric properties of the Dutch Rosenberg self-esteem scale. Psychol. Belg. 48, 25-35.

Franck, E., De Raedt, R., Dereu, M., and Van den Abbeele, D. (2007). Implicit and explicit self-esteem in currently depressed individuals with and without suicidal ideation. J. Behav. Ther Exp. Psychiatry 38, 75-85.

Gawronski, B., and Bodenhausen, G. V. (2006). Associative and propositional processes in evaluation: an integrative review of implicit and explicit attitude change. Psychol. Bull. 132, 692-731.

Greenwald, A. G., and Banaji, M. R. (1995). Implicit social cognition: attitudes, self-esteem, and stereotypes. Psychol. Rev. 102, 4-27.

Greenwald, A. G., McGhee, D. E., and Schwartz, J. K. L. (1998). Measuring individual differences in implicit cognition: the implicit association test. J. Pers. Soc. Psychol. 74, 1464-1480.

Greenwald, A. G., Nosek, B. A., and Banaji, M. R. (2003). Understanding and using the implicit association test: I. An improved scoring algorithm. J. Pers. Soc. Psychol. 85, 197-216.

Harter, S. (1993). "Causes and consequences of low self-esteem in children and adolescents," in SelfEsteem: The Puzzle of Low SelfRegard, ed. R. F. Baumeister (New York: Plenum), 87-116.

Heilbron, N., and Prinstein, M. J. (2010). Adolescent peer victimization, peer status, suicidal ideation, and nonsuicidal self-injury: examining concurrent and longitudinal associations. Merrill Palmer Q. 56, 388-419.

Higbee, K. R., and Roberts, R. E. (1994) Reliability and validity of a brief

can be drawn from this study. Furthermore, the sample consisted only of healthy young woman and future research should examine whether our findings can be generalized to other groups.

\section{ACKNOWLEDGMENTS}

Funding for this study was provided by grants from GGz OostBrabant and The Olim Foundation.

measure of loneliness with AngloAmerican and Mexican American adolescents, Hispanic. J. Behav. Sci. $16,459-474$.

Jordan, C. H., Spencer, S. J., Zanna, M. P., Hoshino-Browne, E., and Correll, J. (2003). Secure and defensive high self-esteem. J. Pers. Soc. Psychol. 85, 969-978.

Kernis, M. H., Lakey, C. E., and Heppner, W. L. (2008). Secure versus fragile high self-esteem as a predictor of verbal defensiveness: converging findings across three different markers. J. Pers. 76, 1-36.

Koole, S. L., Govorun, O., Cheng, C., and Gallucci, M. (2009). Pulling your self together: meditation enhances the congruence between implicit and explicit self-esteem. J. Exp. Soc. Psychol. 45, 1220-1226.

Koole, S. L., and Pelham, B. W. (2003). "On the nature of implicit selfesteem: the case of the name letter effect," in Motivated Social Perception: The Ontario Symposium, Vol. 9, eds S. J. Spencer, S. Fein, M. P. Zanna, and J. M. Olson (Mahwah, NJ: Lawrence Erlbaum), 93-116.

Nosek, B. A., Greenwald, A. G., and Banaji, M. R. (2005). Understanding and using the implicit association test: II. Method variables and construct validity. Pers. Soc. Psychol. Bull. 31, 166-180.

Prinstein, M. J., and La Greca, A. M. (2002). Peer crowd affiliation and internalizing distress in childhood and adolescence: a longitudinal follow-back study. J. Res. Adolesc. 12, 325-351.

Reynolds, W. M. (1988). Suicidal Ideation Questionnaire. Odessa, FL: Psychological Assessment Resources.

Roberts, R. E., Lewinsohn, P. M., and Seeley, J. R. (1993). A brief measure of loneliness suitable for use with adolescents. Psychol. Rep. 72 1379-1391.

Rosenberg, M. (1965). Society and the Adolescent Self-Image. Princeton, NJ: Princeton University Press.

Russell, D., Peplau, L. A., and Cutrona, C. E. (1980). The revised UCLA Loneliness Scale: concurrent and discriminant validity evidence. $J$. Pers. Soc. Psychol. 39, 472-480.

Schröder-Abé, M., Rudolph, A., and Schütz, A. (2007). High implicit self-esteem is not necessarily advantageous: discrepancies between explicit and implicit self-esteem and their relationship with anger expression and psychological health. Eur. J. Pers. 21, 319-339.

Shaffer, D., Fisher, P., Lucas, C. P., Dulcan, M. K., and Schwab-Stone, M. E. (2000). NIMH Diagnostic Interview Schedule for Children Version IV (NIMH DISC-IV): description, differences from previous versions, and reliability of some common diagnoses. J. Am. Acad. Child Adolesc. Psychiatry 39, 28-38.

Sriram, N., and Greenwald,A. G. (2009). The Brief Implicit Association Test. Exp. Psychol. 56, 283-294.

Van der Does, A. J. W. (2002). BDI-II-NL Handleiding. De Nederlandse Versie van de Beck Depression InventorySecond Edition. Lisse: Swets \& Zeitlinger.

Conflict of Interest Statement: The authors declare that the research was conducted in the absence of any commercial or financial relationships that could be construed as a potential conflict of interest.

Received: 04 December 2012; paper pending published: 31 January 2013; accepted: 10 March 2013; published online: 02 April 2013.

Citation: Creemers DHM, Scholte RHJ, Engels RCME, Prinstein MJ and Wiers RW (2013) Damaged selfesteem is associated with internalizing problems. Front. Psychol. 4:152. doi: 10.3389/fpsyg.2013.00152

This article was submitted to Frontiers in Psychopathology, a specialty of Frontiers in Psychology.

Copyright (c) 2013 Creemers, Scholte, Engels, Prinstein and Wiers. This is an open-access article distributed under the terms of the Creative Commons Attribution License, which permits use, distribution and reproduction in other forums, provided the original authors and source are credited and subject to any copyright notices concerning any third-party graphics etc. 


\section{APPENDIX}

Results of the conventional regression analyses and the discrepancy analyses when implicit self-esteem is measured with the Brief-IAT.

Table A1 | Hierarchical multiple regression analyses: associations of explicit self-esteem, implicit self-esteem (Brief-IAT), and the interaction between implicit and explicit self-esteem with suicidal ideation, depressive symptoms, and loneliness.

\begin{tabular}{|c|c|c|c|c|c|c|c|c|}
\hline \multicolumn{3}{|c|}{ Suicidal ideation } & \multicolumn{3}{|c|}{ Depressive symptoms } & \multicolumn{3}{|c|}{ Loneliness } \\
\hline B & SE & $\beta$ & B & SE & $\beta$ & B & SE & $\beta$ \\
\hline 0.01 & 0.01 & $0.19^{\dagger}$ & 0.06 & 0.08 & 0.06 & -0.08 & 0.08 & -0.08 \\
\hline-0.03 & 0.01 & $-0.45^{* *}$ & -0.72 & 0.08 & $-0.72^{* *}$ & -0.65 & 0.08 & $-0.65^{* *}$ \\
\hline-0.01 & 0.01 & -0.11 & 0.08 & 0.06 & 0.11 & 0.09 & 0.06 & 0.11 \\
\hline
\end{tabular}

Suicidal ideation $R^{2}=0.18$ in step $1(p=0.00) ; \Delta R^{2}=0.01$ in step $2(p=0.26)$; depressive symptoms $\Delta R^{2}=0.49$ in step $1(p=0.00) ; \Delta R^{2}=0.01$ in step $2(p=0.16)$; loneliness $\Delta R^{2}=0.46$ in step $1(p=0.00) ; \Delta R^{2}=0.01$ in step $2(p=0.15) ;{ }^{*} p<0.05,{ }^{* *} p<0.01,{ }^{t} p=0.053$.

Table A2 | Hierarchical multiple regression analyses: associations of the size of the discrepancy, direction of the discrepancy, and the interaction between the size of the discrepancy and the direction of the discrepancy with suicidal ideation, depressive symptoms, and loneliness.

\begin{tabular}{|c|c|c|c|c|c|c|c|c|c|}
\hline & \multicolumn{3}{|c|}{ Suicidal ideation } & \multicolumn{3}{|c|}{ Depressive symptoms } & \multicolumn{3}{|c|}{ Loneliness } \\
\hline & B & SE & $\beta$ & B & SE & $\beta$ & B & SE & $\beta$ \\
\hline \multicolumn{10}{|l|}{ STEP 1} \\
\hline Size of the discrepancy & 0.03 & 0.01 & $0.35 * *$ & 0.35 & 0.13 & $0.26 * *$ & 0.09 & 0.14 & 0.06 \\
\hline Direction of the discrepancy & 0.03 & 0.01 & $0.22^{*}$ & 0.65 & 0.19 & $0.33^{* *}$ & 0.43 & 0.20 & $0.21^{*}$ \\
\hline \multicolumn{10}{|l|}{ STEP 2} \\
\hline Size of the discrepancy* & 0.04 & 0.02 & $0.53^{*}$ & 0.75 & 0.27 & $0.59 * *$ & 0.79 & 0.29 & $0.61 * *$ \\
\hline Direction of the discrepancy & & & & & & & & & \\
\hline
\end{tabular}

Suicidal ideation $R^{2}=0.16$ in step $1(p=0.00) ; \Delta R^{2}=0.05$ in step $2(p=0.02)$; depressive symptoms $R^{2}=0.17$ in step $1(p=0.00) ; \Delta R^{2}=0.06$ in step $2(p=0.01)$; Loneliness $R^{2}=0.05$ in step $1(p=0.09) ; \Delta R^{2}=0.07$ in step $2(p=0.01) ;{ }^{*} p<05{ }^{* *} p<01$. Direction of the Discrepancy was dummy coded: $0=$ fragile self-esteem; $1=$ damaged self-esteem. 